\title{
ИНТЕГРАТИВНАЯ РОЛЬ СПЕЦКУРСА В ФОРМИРОВАНИИ ВОЕННО-ПРОФЕССИОНАЛЬНОГО САМООПРЕДЕЛЕНИЯ
}

\section{INTEGRATIVE ROLE OF SPECIAL COURSE IN THE FORMATION OF MILITARY- PROFESSIONAL SELF-DETERMINATION \\ M. Pasynkova I. Romas}

Summary: The organizational and methodical interaction of the school and the university of stages is able to solve the issues of continuity and continuity of vocational education. The article presents a special course "Military-professional training" developed as a pedagogical condition for the formation of military-professional self-determination of students of the specialized Lyceum class of military-patriotic direction. This development plays an integral role in ensuring the military focus of the self-determination of schoolchildren.

Keywords: integration, Conditions for integrating subjects, Components of pedagogical integration, military-professional self-determination, Educational environment integrative role.
Пасынкова Марина Александровна Аспирант, Амурский государственный университет, г. Благовещенск m.pasynckowa@yandex.ru Ромас Игорь Анатольевич К.п.н., доцент, Благовещенский государственный педагогический университет, г. Благовещенск

Аннотация: Организационно-методическое взаимодействие школы и вуза этапов способно решать вопросы преемственности и непрерывности профессионального образования. В статье представлен спецкурс «Военно-профессиональная подготовка», разработанный в качестве педагогического условия формирования военно-профессионального самоопределения учащихся специализированного лицейского класса военно-патриотического направления. Данная разработка играет интегративную роль при обеспечении военной направленности самоопределения школьников.

Ключевые слова: интеграция, условия интеграции учебных предметов, компоненты педагогической интеграции, военно-профессиональное самоопределение, образовательная среда, интегративная роль.
$\mathrm{B}$ озникшая как философская теория, интеграция беспрепятственно проникла во многие науки и, на сегодняшний день, олицетворяет межнаучную теорию. В конце 1980-х г.г. новыми подходами занялись педагоги.

Огромные возможности теории интеграции объясняют повышенное внимание. Так, И.В. Осипова считает, что в образовании она позволяет: во-первых, уплотнить или откорректировать содержание. Во-вторых, можно соединить разрозненные части, формируя целостную картину изучаемых предметов, явлений и свойств. В-третьих, посредством интеграции можно обеспечивать профессиональную направленность обучения. [6]

Н.Б. Симакова утверждает, что «интеграция - общий и многогранный процесс установления связей между информацией, знаниями, науками, а также обеспечение их целостности и единой структуры, охватывающей все компоненты в диалектическом единстве». Также она видит роль интеграции учебных предметов в вариативности, личностной ориентации, формированию целостности знаний учащихся о мире и профилизации обучения на старшей ступени школы непосредственно или через дифференциацию образования.

Н.Б. Симакова выделяет исследования по проблеме интеграции учебных предметов в сфере общего сред- него образования (В.В. Гузеев, Н.Н. Деменева, Е.В. Колесникова, С.А. Сергеенок, О.А. Яворук и др.) и в системе профессионального образования (В.С. Безрукова, М.Н. Берулава, А.П. Беляева, Ю.С. Тюнников, Л.Д. Федотова, Н.К. Чапаев и др.). [8]

В ходе исследования нами выяснено, что, несмотря на давние исторические корни исследования проблемы, до сих пор в науке существует множество подходов к пониманию термина «интеграция». Исходя из общего понимания интеграции в педагогике как процесса, средства и результата взаимосвязи объектов. [9], ключевыми понятиями в определении на современном этапе развития педагогики выступают: взаимосвязь, взаимодополнение, взаимозависимость, взаимодействие.

Взаимодействие, при этом, является системообразующим компонентом, потому что определяет характер процесса интеграции и отношения между ее субъектами. Мы считаем, что интеграция ведет к укрупнению объектов исследования, а главное, к объединению и взаимопроникновению методов исследования.

В педагогике понятие «интеграция», с одной стороны отражается в понятии «связь», как производные: «взаимосвязь», «взаимодействие», «взаимозависимость» (С.И. Архангельский и др.), с другой - «интеграция» по содержанию близка к понятию «целостность» (Г.А. Мона- 
хов и др.); в-третьих, существует мнение о зависимости от отношений между дифференциацией и интеграцией (А.П. Беляева и др.), в-четвертых, рассматривается как системная единица (И.П. Яковлев и др.); в-пятых, - как педагогический феномен (М.Н. Берулава и др.), в-шестых, преподносится через призму дидактических принципов (И.Д. Зверев, В.Н. Максимов, М.М. Левина, Н.А. Лошкарева, В.Т. Фоменко, К.Ю. Колесина и др.), в-седьмых, как дидактическое условие (В.Н. Федорова, А.В. Усова, Д.М. Кирюшкин, А.А. Пинский и др.). [3] Основная идея интеграции, как составляющей педагогической системы - целостное восприятие явлений при их изучении, как писал Я.А. Коменский: «Все, что находится во взаимной связи, должно преподаваться в такой связи» [2].

Современные ученые изучают разные стороны интеграции в учебном процессе:

- интеграция рассматривается и изучается как педагогическая категория (М.Н. Берулава, С.В. Васильева, К.Ю. Колесина, С.С. Пичугин);

- выявляются особенности и возможности создания связей между учебными дисциплинами (Н.С. Антонов, П.Г. Кулагин, В.Н. Федорова);

- исследуется роль и место межпредметных связей (И.Д. Зверев, А.Я. Данилюк, Н.А. Лошкарева, В.П. Максимова, П.Н. Новиков);

- реализуется идея о необходимости интеграции содержания учебных дисциплин для получения целостных знаний (А.И. Гурьев, П.Г. Кулагин);

- изучаются методы изложения учебного материала преподавателем при интегративном подходе (И.Д. Зверев, В.П. Максимова).

М.А. Адамко выделила следующие компоненты педагогической интеграции, существующие в различных вариантах:

- внутрипредметная и межпредметная интеграция. Внутрипредметная интеграция позволяет интегрировать понятия, знания, умения внутри дисциплин, способствует расширению содержания предмета. Межпредметная - представляет синтез фактов, понятий, теории нескольких дисциплин;

- горизонтальный и вертикальный тематизм. В качестве содержательной единицы обучения выступает тема, взаимосвязанная содержанием, смыслом и эмоциональным состоянием с другими учебными дисциплинами;

- межсистемная и транспредметная интеграция. Межсистемная представляет объединение содержания обучения в единое целое с дополнительным образованием. Транспредметная является синтезом элементов, включающих основное и дополнительное содержание образования;

- интегрированные курсы, их основа - дисциплины, которые входят в различные, но близкие образовательные области. [1]
Используя названные компоненты, возможно осуществлять преемственность и непрерывность профессионального образования.

Лукашенко М., описывая несколько моделей Регионального опыта, приводит пример вертикальной интеграции при реализации модели «школа - вуз», которая включает в себя: подготовительные курсы на базе вуза; подготовительные курсы на базе школ (классы, спрофилированные на вуз); специализированные классы (сочетание подготовки в вуз и профориентационной программы, подготовки в вуз и психологического образования и т.д.); лицейские классы (углубленное изучение специальных дисциплин по экспериментальному учебному плану; подготовка школьников к обучению в вузе по индивидуальному учебному плану, не исключающему сокращение сроков обучения). [4]

Изучение теоретического и практического материала в совокупности с собственным опытом исследования условий формирования военно-профессионального самоопределения выявило пути вертикализации военного обучения.

Педагогический комплекс, разработанный на основе партнерства Муниципального автономного образовательного учреждения «Лицей № 6 города Благовещенска» и Дальневосточного высшего общевойскового командного училища имени маршала Советского Союза К.К. Рокоссовского способен расширить возможности эффективности формирования военно-профессионального самоопределения учащихся кадетских классов военно-патриотической направленности. Занятия, проводимые на территории и под руководством профессорско-преподавательского состава Дальневосточного высшего общевойскового командного училища, обеспечат погружение в военно-профессиональную среду.

Комплекс мероприятий партнерского взаимодействия образовательных учреждений разного уровня призван организовать военно-профессиональную образовательную среду, раскрывающую новые возможности повышения уровня военно-профессионального самоопределения школьников. При этом спецкурс «Военно-профессиональная подготовка» в учебно-воспитательном процессе специализированного военно-патриотического класса «Рокоссовец» станет условием формирования военно-профессионального самоопределения.

Спецкурс «Военно-профессиональная подготовка» разработан в соответствии с договором о совместной деятельности Ресурсного центра по обучению граждан начальным знаниям в области обороны и подготовки к основам военной службы. 
Его основная роль - мотивационно связать образовательные программы учащихся специализированного военно-патриотического класса «Рокоссовец» муниципального образовательного автономного учреждения лицей № 6 (МОАУ лицей № 6) и рабочие программы по дисциплинам, преподаваемым в Дальневосточном высшем общевойсковом командном училище имени Маршала Советского Союза К.К. Рокоссовского.

Целями преподавания спецкурса «Военно-профессиональная подготовка» были обозначены:

- воспитание истинного патриота России, готового мужественно защищать независимость и конституционный строй России, народ и Отечество, дисциплинированного, решительного, смелого, инициативного, выносливого, способного переносить тяготы военной службы;

- получение учащимися необходимых знаний для его будущей профессиональной деятельности;

- выявление профессионально важных навыков.

Нами были сформулированы задачи преподавания спецкурса «Военно-профессиональная подготовка»:

- формирование у подрастающего поколения внутренней мотивации к профессиональной деятельности в рядах Вооруженных Сил РФ, позитивного образа военнослужащего, понимания общественной необходимости военной службы;

- воспитание у школьников морально-психологических, физических качеств и правовой культуры, необходимых для службы в Вооруженных Силах PФ;

- формирование у школьников смелости, решительности, дисциплинированности, ответственности за порученное дело, готовности к обороне страны;

- формирование знаний и умений, позволяющих быстро адаптироваться в сложных ситуациях повседневной деятельности, профилактика девиантного поведения;

- осуществление военно-профессиональной ориентации и подготовки школьников к поступлению в образовательные учреждения высшего профессионального образования Министерства обороны РФ.

Как результат проведения спецкурса «Военно-профессиональная подготовка» на базе специализированного военно-патриотического класса «Рокоссовец» (МОАУ лицей № 6) обучаемые должны знать:

- организационно-штатную структуру подразделений военнослужащих и иерархию подчиненности в Вооруженных Силах Российской Федерации;

- структуру военного образования РФ и организация образовательного процесса. Требования приема в военные образовательные учреждения.
- виды уставов ВС РФ и их предназначение;

- права и ответственность военнослужащих Российской Федерации, их обязанности при прохождении военной службы;

- традиции Вооруженных Сил Российской Федерации;

- основные события военной истории Отечества и зарубежных государств;

- основные направления эволюции военного искусства и вооружения;

- закономерности психического развития человека и формы их особых проявлений у военнослужащих;

- современные требования к организации работы с военнослужащими;

- особенности психических состояний военнослужащих;

а также уметь:

- различать воинские звания Вооруженных Сил Российской Федерации;

- составлять необходимые документы для взаимодействия с военными образовательными учреждениями Вооруженных Сил Российской Федерации;

- ориентироваться в содержании уставов ВС РФ;

- различать виды ответственности гражданина Российской Федерации и военнослужащего в Вооруженных Силах РФ;

- проводить анализ исторических событий, делать обоснованные выводы из исторического опыта для практического применения его в военно-профессиональной деятельности;

- организовывать психологическую работу;

- грамотно использовать результаты изучения индивидуальных психологических особенностей военнослужащих.

При разработке и реализации спецкурса «Военнопрофессиональная подготовка» мы руководствовались педагогическими принципами: гуманизации; демократизации; принципом природосообразности; культуросообразности; наглядности; доступности; принципом прочности; научности; принципом связи теории с практикой; принципом воспитывающего обучения; сознательности, активности, творчества и инициативы; принципом субъектности.

Вопросы спецкурса «Военно-профессиональная подготовка» составлены на основе вышеизложенных педагогических принципов и сгруппированы как дидактические единицы.

Тема 1. Война. Вооруженный конфликт. Основные события в истории ВС РФ. Профессиональные праздники. 


\section{Тема 2. История оружия.}

Тема 3. Структура военного образования РФ. Требования приема в военные образовательные учреждения.

Тема 4. Самодиагностика профессионально-важных качеств.

Тема 5. Определение военно-профессиональной направленности. Тактическое мышление.

Тема 6. Организационно-штатная структура подразделений военнослужащих и воинские звания в Вооруженных Силах Российской Федерации. Форма одежды, знаки различия военнослужащих.

Тема 7. Виды уставов ВС РФ и их предназначение.

Тема 8. Права и ответственность военнослужащих. Основные обязанности при прохождении военной службы. Льготы военнослужащих.

На проведение спецкурса, при распределении учебного времени, выделенного на работу обучающихся с преподавателем и на самостоятельную работу, программой предусмотрено 16 учебных часов.

Занятие 1 «Война. Вооруженный конфликт. Основные события в истории ВС РФ. Профессиональные праздники» проводилось на территории Дальневосточного высшего общевойскового училища в виде лекции. Занятие велось под руководством преподавателя ДВОКУ по военной истории. Привлекались курсанты-участники военно-научного общества.

Занятие 2 «История оружия» было организовано и проведено в форме лекции-беседы преподавателем кафедры вооружения и стрельбы с последующей экскурсией в музей ДВОКУ.

Занятие 3 - лекция: «Структура военного образования РФ. Требования приема в военные образовательные учреждения» проводилась в учебном классе кафедры тактики. С возможностью конспектировать или зарисовывать в тетрадях.

Занятие 4. «Самодиагностика профессионально-важных качеств» разрабатывалось совместно с начальником группы профессионального психологического отбора. В результате сотрудничества была разработана необходимая для более эффективной профориентационной работы линия подачи материала.

В ходе занятия с учащимися проводился, в качестве демонстрации, тренинг, состоящий из методик: «Устный счет» и «Градусник». Данный тренинг является модификацией методики «Арифметический счет» [5]. Эту ме- тодику рекомендуется применять при обследовании способности к преобразованию цифровой информации и готовности выполнять интеллектуальные операции в повышенном темпе.

«Устный счет» является мультимедийной наглядной методикой, предназначенной для активизации мыслительных процессов и точности переработки информации при выполнении простых арифметических действий. Его возможно использовать как при работе с группой, так и индивидуально.

Включение такой практической работы стимулирует интерес к занятию и учит участников мобилизации своих возможностей. В ходе проведения практической работы мы имеем возможность научить испытуемых дифференцировать сложные задачи или массивы информации и преодолевать их поэтапно, что приведет к улучшению успеваемости и повышению самооценки учащихся.

Занятие 5 «Определение военно-профессиональной направленности. Тактическое мышление» проводилось совместно с начальником группы профессионального психологического отбора с целью ознакомления учащихся специализированного военно-патриотического класса с необходимостью и тенденциями в диагностике военно-профессиональной направленности претендентов на зачисление в военные образовательные учреждения Вооруженных Сил Российской Федерации.

Занятие 6 «Организационно-штатная структура подразделений военнослужащих и воинские звания в Вооруженных Силах Российской Федерации. Форма одежды, знаки различия военнослужащих» проводилось в учебном классе кафедры тактики ДВОКУ. В ходе беседы были продемонстрированы: структура воинских подразделений, обусловленность строгого соблюдения установленной формы одежды и соответствия знаков различия военнослужащих воинским званиям.

Занятие 7 «Виды уставов ВС РФ и их предназначение» организовано и проводилось на полигоне Дальневосточного высшего общевойскового командного училища. В обстановке, приближенной к условиям пребывания на полевых военно-учебных занятиях учащиеся знакомились с предназначением уставов Вооруженных Сил Российской федерации. Для обеспечения занятия библиотекой была предоставлена соответствующая литература.

Занятие 8 «Права и ответственность военнослужащих. Основные обязанности при прохождении военной службы. Льготы военнослужащих» было проведено при содействии начальника отдела (организации научной работы и редакционно-издательской деятельности). 


\begin{tabular}{|c|c|c|c|c|}
\hline $\begin{array}{c}\text { Учебные предметы на } \\
\text { довузовскем этапе }\end{array}$ & & $\begin{array}{c}\text { Спецкурс «Военно- } \\
\text { професспональная } \\
\text { подтотовка» }\end{array}$ & & $\begin{array}{c}\text { Уqебные дисцитлины высшего } \\
\text { военно-професспонального } \\
\text { образованшя }\end{array}$ \\
\hline $\begin{array}{l}\text { Исторня Россин. } \\
\text { Всеобщая история. } \\
\text { География. } \\
\text { Изобразительное } \\
\text { искусство. }\end{array}$ & 4 & $\begin{array}{l}\text { Война. Вооруженный } \\
\text { конфликт. Основные события } \\
\text { в истории ВС РФ. } \\
\text { Профессиональные праздники }\end{array}$ & & $\begin{array}{l}\text { Культурология. } \\
\text { Военная история. } \\
\text { Социология. } \\
\text { Иеторня. }\end{array}$ \\
\hline $\begin{array}{l}\text { История России. } \\
\text { Всеобщая нсторня. } \\
\text { География. } \\
\text { Информатика. } \\
\text { Физика. } \\
\text { Биология. } \\
\text { Химия. } \\
\text { Технологня. } \\
\text { Основы безопасности } \\
\text { жизнедеятельности. }\end{array}$ & $\rightleftarrows$ & Ксторня оружия & $\Longrightarrow$ & $\begin{array}{l}\text { Военная история. } \\
\text { Основы вьгкиваемости. } \\
\text { Информатика. } \\
\text { Физика. } \\
\text { Техническая механика. } \\
\text { Инженерная графика. }\end{array}$ \\
\hline $\begin{array}{l}\text { Обществознание. } \\
\text { Физическая культура. } \\
\text { Основы безопасности } \\
\text { жнзнедеятельности. }\end{array}$ & & $\begin{array}{l}\text { Cтруктура военного } \\
\text { образования РФ. Требования } \\
\text { приема в военные } \\
\text { образовательные учреждения. } \\
\text { Обзорное занятне }\end{array}$ & & $\begin{array}{l}\text { Военная нсторня. } \\
\text { Экономика. } \\
\text { Политология. } \\
\text { Социология. } \\
\text { Фнзическая подготовка. }\end{array}$ \\
\hline $\begin{array}{l}\text { Основы } \\
\text { психологнческих } \\
\text { знаний. } \\
\text { Биология. }\end{array}$ & & $\begin{array}{l}\text { Самоднагностнка } \\
\text { профессионально-важньх } \\
\text { качеств }\end{array}$ & $\Rightarrow$ & $\begin{array}{l}\text { Психология и педагогика. } \\
\text { Организация работы с личным } \\
\text { составом в ВС РФ. } \\
\text { Физическая поднотовка. }\end{array}$ \\
\hline $\begin{array}{l}\text { Основы } \\
\text { психологических } \\
\text { знаннй. } \\
\text { Математика. Aлгебра. } \\
\text { Геометрия. } \\
\text { Фнзнка }\end{array}$ & $\nLeftarrow$ & $\begin{array}{l}\text { Определение военно- } \\
\text { профессионатьной } \\
\text { направленности. Тактическое } \\
\text { мьшпление }\end{array}$ & & $\begin{array}{l}\text { Психология и педагогика. } \\
\text { Организация работы с личньм } \\
\text { составом в ВС РФ. } \\
\text { Психофизиология } \\
\text { профессионатьной деятельности. }\end{array}$ \\
\hline $\begin{array}{l}\text { Обществознание. } \\
\text { Изобразительное } \\
\text { нскусство. }\end{array}$ & $\longleftarrow$ & $\begin{array}{l}\text { Oрганизационно-штатная } \\
\text { структура подразделений } \\
\text { военнослужаших и воннскне } \\
\text { звания в Вооруженньх Снлах } \\
\text { Российской Федерации. } \\
\text { Форма одежды, знаки } \\
\text { различня военнослужащих. } \\
\text { Обзорное занятие }\end{array}$ & & $\begin{array}{l}\text { Культурология. } \\
\text { Военная исторня. } \\
\text { Политология. } \\
\text { Психология и педагогика. } \\
\text { Организация работы с личньм } \\
\text { составом в ВС Р } Ф \text {. } \\
\text { Правоведение. }\end{array}$ \\
\hline Обществознание & & $\begin{array}{l}\text { Внды уставов ВС РФ н их } \\
\text { предназначение. Обзорное } \\
\text { занятие }\end{array}$ & & $\begin{array}{l}\text { Военная нсторня. } \\
\text { Политология. } \\
\text { Правоведение. }\end{array}$ \\
\hline $\begin{array}{l}\text { Обществознание. } \\
\text { Физнческая культура. } \\
\text { Основы безопасности } \\
\text { жизнедеятельности. }\end{array}$ & & $\begin{array}{l}\text { Права и ответственность } \\
\text { военнослужащих. Основные } \\
\text { обязанности при прохождении } \\
\text { военной службы. Лыготы } \\
\text { военнослужашнх }\end{array}$ & & $\begin{array}{l}\text { Военная нсторня. } \\
\text { Экономика. } \\
\text { Политология. } \\
\text { Организация работы с личньм } \\
\text { составом в ВС РФ. } \\
\text { Правоведение. } \\
\text { Фнзнческая подготовка. } \\
\text { Основы вьгкивемости. } \\
\text { Строевая подготовка. }\end{array}$ \\
\hline
\end{tabular}

Рис. 1. Связь учебных предметов общеобразовательной школы с учебными дисциплинами военного учреждения высшего образования при помощи дидактических единиц спецкурса «Военно-профессиональная подготовка»

Подводя итог проделанной работы, можно сделать вывод, что разработанный нами спецкурс явился условием военно-профессионального самоопределения учащихся специализированного военно-патриотического класса «Рокоссовец» (МОАУ лицей № 6). Во-первых, занятия планировались с целью мотивационно-ценностной ориентации учащихся на военно-профессиональную деятельность. Во-вторых, занятия на территории и с участием административно-преподавательского состава ДВОКУ усилили интегративную роль учебных предметов общеобразовательной школы с дисциплинами военного учреждения высшего образования.

Интегративная роль спецкурса «Военно-профессио- нальная подготовка» просматривается на уровне дидактических единиц (рисунок).

Так, дидактические единицы: «Права и ответственность военнослужащих» и «Основные обязанности при прохождении военной службы» в процессе преподавания в классах оборонно-спортивного направления по подбору военно-профессионального ориентированного материала обеспечивают связь учебных предметов: обществознание, физическая культура, основы безопасности жизнедеятельности на довузовском этапе с дисциплинами: военная история, экономика, политология, организация работы с личным составом в ВС РФ, правоведение, физическая подготовка, основы выживаемо- 
сти, строевая подготовка военного учреждения высшего образования.

Вывод: В процессе внедрения в образовательный процесс специализированного военно-патриотического класса «Рокоссовец» (МОАУ лицей № 6) нами продемонстрирована интегративная роль спецкурса «Военнопрофессиональная подготовка».

Достигнуты определенные нами цели интеграции дисциплин на разных ступенях образования:

- использование разработанного спецкурса как когнитивное дополнение военно-направленного школьного образования;

- обеспечение, в специализированных классах, связи общеобразовательных предметов общеобразовательной школы с дисциплинами, преподаваемыми в военном вузе:

Решены поставленные задачи интеграции дисциплин:

1. акцентировать внимание на необходимости как начальных военно-профессиональных знаний и умений, так и подготовки по общеобразовательным предметам;

2. продемонстрировать учащимся значимость саморазвития для профессионального самоопределе- ния и дальнейшего личностного роста.

При реализации спецкурса «Военно-профессиональная подготовка» использовались формы: классно-урочная, внеклассная, при этом предусматривалась работа как групповая, так и индивидуальная. Нами были применены опробированные методы, которые можно разбить на четыре основных группы: обучения и воспитания, ориентационной работы учащихся, управления, диагностики. [7]

Средствами осуществления интеграции учебных предметов общеобразовательной школы с дисциплинами военного учреждения высшего образования послужили: предоставленные учебные аудитории и площади, специальным образом оснащенные стандартным и интерактивным оборудованием. Использовались: фактологический материал, интерактивная демонстрация конкретных исторических событий из собственных разработок и преподавателей ДВОКУ.

В процессе ведения данного курса нами была глобализирована проблема предназначения вооруженных сил, акцентирована моральная ответственность за самостоятельный профессиональный выбор каждого учащегося.

ЛИТЕРАТУРА

1. Адамко М.А. Содержательные аспекты интегративного подхода в вузовском процессе изучения английского языка/Вестник ТвГУ. Серия "Педагогика и психология". 2016. № 3. С 96-104

2. Бусыгина А.Л. Совершенствование педагогической компетентности преподавателей как фактор повышения эффективности учебного процесса ВТУЗа: дис. .... канд. пед. наук. СПб., 1994. 189 с., с. 34-38

3. Бычкова 0.И. Развитие педагогических умений будущего учителя в процессе интеграции учебных дисциплин: автореферат дис. кандидата педагогических наук: 13.00.01 / Бычкова Ольга Ивановна; [Место защиты: Иркутский гос. пед. ун-т]. - Иркутск, 2004. - 20с.

4. Лукашенко М. Вертикальная интеграция в системе образования // Высшее образование в России. 2002. №3. C 10-24. URL: https://cyberleninka.ru/ article/n/vertikalnaya-integratsiya-v-sisteme-obrazovaniуа (дата обращения: 11.02.2021).

5. Методические рекомендации по организации и проведению профессионального психологического отбора в военно-учебных заведениях Министерства Обороны Российской Федерации, 2002 г

6. Осипова И.В. Реализация принципа интеграции при подготовке педагога профессионального обучения / И.В. Осипова, М.А. Черепанов // Вестник Учебнометодического объединения по профессионально-педагогическому образованию / Рос. гос. проф.-пед. ун-т. - Екатеринбург, 2003. - Вып. 1 (32). - С. 18-24.

7. Протасова Н.Б. Педагогические условия профессионального самоопределения учащихся в системе "гимназия-вуз": диссертация ... кандидата педагогических наук: 13.00.01/ Протасова Надежда Борисовна; [Место защиты: Марийс. гос. ун-т].- Йошкар-0ла, 2012.- 181 с. С 35-36.

8. Симакова Н.Б. Интеграция предметов естественнонаучного цикла как средство формирования целостного миропонимания школьников: автореферат дис. кандидата педагогических наук: 13.00.01 / Симакова Надежда Борисовна; [Место защиты: Удмуртский гос. ун-т]. - Ижевск 2005 - 19 с

9. Системообразующие понятия в реализации педагогической интеграции: Метод, рекомендации / Под ред. В.С. Безруковой. Свердловск, 1988. - 20 с.

(c) Пасынкова Марина Александровна (m.pasynckowa@yandex.ru), Ромас Игорь Анатольевич.

Журнал «Современная наука: актуальные проблемы теории и практики» 